\title{
Lactational amenhorrhoea method for birth spacing in Uttar Pradesh, India: Supporting technical data
}

\author{
Leila Caleb-Varkey \\ Population Council \\ John Townsend \\ Population Council
}

Follow this and additional works at: https://knowledgecommons.popcouncil.org/departments_sbsr-rh

Part of the Demography, Population, and Ecology Commons, International Public Health Commons, and the Maternal and Child Health Commons How does access to this work benefit you? Let us know!

\section{Recommended Citation}

Caleb-Varkey, Leila and John Townsend. 1996. "Lactational amenhorrhoea method for birth spacing in Uttar Pradesh, India: Supporting technical data," Policy Brief. New Delhi: Population Council. 


\title{
POLICY BRIEF
}

\author{
LACTATIONAL AMENORRHOEA METHOD \\ FOR BIRTH SPACING IN UTTAR PRADESH, \\ INDIA
}

\author{
Supporting Technical Data \\ Leila E. Caleb \\ John W. Townsend
}

\section{The Population Council \\ Asia \& Near East}

Operations Research and Technical Assistance Project New Delhi, India 


\section{CONTENTS}

$\begin{array}{ll}\text { I. Introduction } & 1\end{array}$

II. Background: Birth Spacing in Uttar Pradesh 2

III. Postpartum Contraception 3

A. Contraceptive options 3

B. The Fertility-inhibiting effect of Breastfeeding: LAM 4

IV. Data on Breastfeeding, Susceptibility and LAM in UP 5

A. Postpartum abstinence 6

B. Frequency of Breastfeeding Episodes 7

C. Reasons for early Discontinuation 8

V. Guidelines for Operational Policies to include LAM in UP 9

VI. Operational Issues for Service Delivery 11

$\begin{array}{ll}\text { VII. Conclusion } & 12\end{array}$

$\begin{array}{ll}\text { References } & 13\end{array}$

$\begin{array}{ll}\text { Policy Brief Pullout } & 16\end{array}$ 


\title{
POLICY BRIEF
}

\section{THE LACTATIONAL AMENORRHOEA Method (LAM) FOR BIRTH SPACING IN UTTAR PRADESH, INDIA}

\author{
Supporting Technical Data
}

\section{INTRODUCTION}

Following the International Population and Development Conference in Cairo, there is widespread consensus in the international community that family planning programs must be people-centered, and further, that family planning programs should focus not just on contraception per se, but on the reproductive health of both men and women throughout their lives. This paper reviews the research and policy implications of promoting the Lactational Amenorrhea Method (LAM) as a component of family planning counselling in India.

The Government of India and the Population Council is using a pregnancy based approach in Uttar Pradesh to improve the delivery of family planning services through the rural primary health care system. Introducing pregnant women and their families to the Lactational Amenorrhoea Method (LAM) offers a number of health benefits for both mother and child. It promotes breastfeeding, which benefits the mother by reducing her risk of postpartum hemorrhage and lowering her risk of breast and ovarian cancers. The benefits to the fully breastfed infant include protection from hypothermia, neonatal hypoglycaemia, and infections besides nutritional advantages. Such infants also have a much lower risk of diarrhoea and respiratory infections than babies who are not exclusively breastfed (WHO, 1994). And finally, breastfeeding reduces postpartum fertility, thus delaying the need to use other contraceptive methods postpartum. Supporting and promoting LAM introduces couples to the concept of non-permanent contraception and child spacing in a culturally acceptable way.

In Uttar Pradesh, where the crude birth rate is 36.2 per 1000 (NFHS, 1995), an estimate of more than 10 percent of women in the reproductive age group will be pregnant at any given time. However, pregnant women are rarely provided with information on the choice of non-permanent contraceptive methods available to them in the future. In fact, the health care system is more likely to come in contact with women during their pregnancy than at any other time. In a pregnancy-based approach, health care providers can build on their already established rapport with pregnant women to introduce information on contraceptive methods appropriate to the postpartum period and encourage full breastfeeding for the first four to six months of their infant's life. Full breastfeeding is defined as exclusive and nearly exclusive breastfeeds with intervals not exceeding 4 hours during the day and 6 hours at night with few supplements added (Labbok, et al., 1994). LAM should therefore be added to the choice of contraceptive methods available in the National Family Welfare Programme. 


\section{BACKGROUND: Birth Spacing in Uttar Pradesh}

The National Family Health Survey (NFHS, 1995) found that less than 10 percent of women between the age of 20 and 29 use spacing methods. Further, the baseline survey in Uttar Pradesh (BSUP, 1995) for Sitapur District revealed that tubectomies are the most common form of contraception used: nine percent of all married women of reproductive age have been sterilized. Less than one percent of women who had given birth within the past six months reported being sterilized, however. At the same time, the BSUP for Sitapur found that use of contraception at four months postpartum is only 3.4 percent for modern methods and 4.1 percent for other traditional methods and, even more importantly, increases to only 7.3 percent and 7.6 percent respectively at two years postpartum (Table 1). This very low use of spacing methods by UP women in their peak reproductive years indicates the importance of focusing programmatic efforts on meeting the health needs for child spacing and meeting the unmet spacing needs of young married women.

It is known that lactational amenorrhoea alone affords up to one-third of the protection afforded by all of the modern contraceptives in use in the same period (Thapa, Short and Potts, 1988).

Table 1: Current Contraceptive Use in Sitapur District, Uttar Pradesh

\begin{tabular}{|c|c|c|c|c|c|}
\hline \multirow[t]{2}{*}{ Method of contraception } & \multirow{2}{*}{$\begin{array}{l}\text { All currently } \\
\text { married women } \\
\text { (BSUP) }\end{array}$} & \multicolumn{4}{|c|}{$\%$ of women contracepting after a live birth in the past } \\
\hline & & $\begin{array}{l}4 \text { months } \\
(N=269)\end{array}$ & $\begin{array}{l}6 \text { months } \\
(N=362)\end{array}$ & $\begin{array}{l}12 \text { months } \\
(N=651)\end{array}$ & $\begin{array}{l}24 \text { month } \\
(N=1087)\end{array}$ \\
\hline $\begin{array}{c}\text { Modern Methods } \\
\text { Vasectomy } \\
\text { Tubectomy } \\
\text { IUD } \\
\text { OCP } \\
\text { CC } \\
\text { Injection } \\
\end{array}$ & $\begin{array}{l}0.8 \\
9.1 \\
0.7 \\
1.1 \\
3.1 \\
0.2\end{array}$ & $\begin{array}{l}0.0 \\
1.1 \\
0.0 \\
0.4 \\
1.5 \\
0.4\end{array}$ & $\begin{array}{c}0 \\
0.8 \\
0.0 \\
0.6 \\
1.7 \\
0.3\end{array}$ & $\begin{array}{c}0 \\
1.2 \\
0.2 \\
1.1 \\
1.8 \\
0.3\end{array}$ & $\begin{array}{c}0 \\
1.8 \\
0.8 \\
1.1 \\
3.4 \\
0.2\end{array}$ \\
\hline Total: Modern methods & 15.0 & 3.4 & 3.4 & 4.6 & 7.3 \\
\hline $\begin{array}{l}\text { Traditional } \\
\text { Withdrawal } \\
\text { Safe period } \\
\text { Abstinence } \\
\text { Others }\end{array}$ & $\begin{array}{c}4.0 \\
1.8 \text { (safe } \\
\text { period \& } \\
\text { abstinence) } \\
1.4 \\
\end{array}$ & $\begin{array}{l}2.6 \\
0.4 \\
- \\
1.1\end{array}$ & $\begin{array}{l}3.2 \\
1.2 \\
0.3 \\
0.3\end{array}$ & $\begin{array}{l}4.2 \\
1.4 \\
0.6 \\
0.2\end{array}$ & $\begin{array}{l}4.7 \\
1.9 \\
0.6 \\
0.4\end{array}$ \\
\hline Total: Traditional methods & 7.2 & 4.1 & 5.0 & 6.4 & 7.6 \\
\hline Total: All Methods & 22.2 & 7.5 & 8.4 & 11.0 & 14.9 \\
\hline
\end{tabular}

Source:SITAPUR District Level Baseline Survey of Family Planning Programme in Uttar Pradesh, 1995. SIFPSA, Population Council and Operations Research Group.

Analysis of data from eastern Uttar Pradesh showed that if postpartum amenorrhoea dropped from 9.4 months to 7 months, contraceptive prevalence would increase to 31.1 percent from the baseline estimate of 24.9 percent in order to maintain a TFR of 5.4 (Karra and Spieler, 1992). 


\section{POSTPARTUM CONTRACEPTION}

There has been a long tradition of postpartum contraception in India. The national Postpartum Programme established in the 1960s was designed to specifically address the contraceptive needs of couples during this time. Unfortunately, it has been a programme provided through institutional settings while most births occur at home. Like other aspects of the National Family Welfare Programme, the postpartum programme has become largely a postpartum sterilization programme. Efforts to counsel couples on the benefits of spacing births, and the choices of modern and traditional methods available to them to do so, have not been made. This is reflected in the NFHS data which shows that only 6.8 percent of women in the age group 13-49 currently use any modern spacing method (NFHS, 1995), despite many contraceptive methods available to postpartum women. There are two issues of importance when considering postpartum contraception. These are: (1) contraceptive options available in the postpartum period and their influence on lactation, and (2) the fertility decreasing effect of breastfeeding itself. The following paragraphs briefly discuss these issues.

\section{A. Contraceptive Options}

Contraception in the postpartum period poses unique challenges because of the physiological changes in the location and size of the uterus, ovulation, and also because of the hormonal feedback mechanism of lactation. One study of postpartum ovulation and menstruation covered 20 percent of the women who bottlefed their babies and 45 percent of breastfeeders (Howie et al., 1982). These issues have been clearly dealt with in the development and use of contraceptive technology, and satisfactory solutions have been incorporated into policy.

Contraceptive options available in the early postpartum period that do not interfere with lactation include: the intrauterine contraceptive device (IUD), condoms, spermicidal creams and suppositories, diaphragms and sterilization. The recommended time of insertion of an IUD is either immediately after the expulsion of the placenta or after 6 weeks postpartum (Hatcher et al., 1994). Similarly, tubectomies should be performed either immediately postpartum or not before 6 weeks postpartum. This six week time period represents the time it takes for the uterus to return to its normal pelvic placement.

Combined oral contraceptive (COC) pills are not recommended for at least the first six months postpartum or while the infant is predominantly reliant on breastmilk for nourishment, because the estrogen component of combined oral contraceptive pills disturbs the physiology of lactation, reducing volume and caloric content of breast milk and changing its mineral composition (Hull, 1981; WHO Task Force, 1990). However, once the mother starts menstruating and food supplements have been introduced in the infant's diet, the need for contraception should be reassessed and COCs may be added to the choice available. The dosage of contraceptive ethinyl estradiol (about $10 \mathrm{ng}$ per day) reaching the infant of a mother taking COCs is comparable to the dose of naturally occurring estradiol consumed by nursing infants of ovulatory mothers not taking oral contraceptives. The quantity of progestin also varies with type of progestin used in oral pills. The 19-nor compounds (such as norgestrel and norethisterone used in Mala-D and 
Mala-N) enter the milk at only one tenth of the level in the blood (Toddywalla et al., 1980). The non-optimal use of COCs by lactating women is, however, a minor problem. For example, only one percent of women in Sitapur District of UP use COCs in total, and use in the first six months postpartum is minimal.

Progestin-based contraceptives such as progestin-only pills (POP) or mini-pills, DMPA and implants do not adversely influence lactation and may be used after 6 to 12 weeks postpartum. However, they are not part of the options currently available in the National Family Welfare Programme. Barrier methods are also appropriate. Because of irregularity in menstrual periods during the postpartum period, menstrual cycle dependent methods such as calendar rhythm are not recommended.

\section{B. The Fertility-inhibiting Effect of Breastfeeding: Lactational Amenorrhoea Method (LAM)}

The Lactational Amenorrhoea Method (LAM) is the name given to a specific method of contraception in the postpartum period that utilizes the temporary infertility caused by breastfeeding. The constant and high levels of prolactin reached during lactation appear to suppress the production of Follicle Stimulating Hormone (FSH) and Luteinizing Hormone (LH) that in turn prevent menstruation and ovulation (Winikoff et al., 1988). A consensus on the conditions under which lactation would be considered a safe method for contraception was reached at two conferences, held at Bellagio in 1988 and 1995 and at Georgetown University in 1989. These led to wide recognition of what is now known as the Lactational Amenorrhoea Method (LAM). The method states that if the following three conditions are met, the risk of pregnancy in the first 6 months postpartum would be less than two percent (Kennedy, Rivera and McNeilly, 1989).

- Amenorrhoeic

- Fully or nearly fully breastfeeding

- Less than six months postpartum

The effectiveness of this method declines if any one of the conditions is not met. The guidelines for LAM include the advice that- "women who no longer meet these three criteria, or no longer wish to use LAM, should immediately initiate the use of another family planning method if they wish to avoid pregnancy", and that a fourth parameter the timely introduction of another contraceptive method begins when any one of the criteria changes (Labbok et al., 1994). This requires that the woman uses another family planning method to ensure contraceptive continuity to avoid the risk of an unplanned pregnancy. It is recommended that she discusses spacing with her spouse.

It is known that the fertility inhibiting effect of lactation is linked with the milk letdown reflex which is a direct result of the suckling stimulus. Therefore, the duration and frequency of breastfeeds are an important predictor of the effectiveness of lactation as a contraceptive. Research on LAM has found that full or nearly full breastfeeding is most effective. The need to practise full or nearly full breastfeeding is very important when promoting LAM, as cultural definitions of breastfeeding vary from putting the baby to the breast whenever it cries to feeding only once at night. 


\section{DATA ON BREASTFEEDING, SUSCEPTIBILITY AND LAM IN UTTAR PRADESH}

Research points to the need for a better understanding of the current pattern of breastfeeding and postpartum contraception in the region when introducing a change in practice. The importance of counselling for postpartum contraception cannot be over emphasized. Because of the importance of breastfeeding to the health of the infant, one of the goals of postpartum family planning counselling is to insure that clients understand that, although once the conditions for LAM are not met and breastfeeding no longer provides adequate protection from the risk of pregnancy, there is no need to stop breastfeeding in order to use contraceptives. In fact, lactation, no matter how variably practised, should be continued because it benefits the infant and mother.

Research on the Lactational Amenorrhoea Method has provided clear guidelines on when to start using a modern method of contraception while continuing to breastfeed. This is especially important because there is evidence that, unless specifically addressed, some women may assume that they should stop breastfeeding in order to begin contraception. Lactational amenorrhoea alone has also been studied. For example, a study on contraceptive prevalence and breastfeeding in Bangladesh showed that the net effect of early introduction of oral pills was a shorter birth interval (Bhatia and Kim, 1984), because the women who adopted the method earlier were likely to discontinue the method earlier and, as a consequence, did not have the added protection of a longer duration of breastfeeding. However, these findings are not universally true. Another study based on DHS data from peninsular Malaysia found that contraception had no significant relationship with breastfeeding status (RamaRao, 1992).

There has been considerable debate about the wisdom of offering LAM as a contraceptive method to individual couples because the onset of menses and initiation of complementary feeds in the infant's diet cannot be easily predicted by women, and because of, the possible influence of LAM on delaying decisions for use of other spacing methods (Trussell and Santow, 1991; Bracher, 1992). It is important that LAM be considered one of many choices available to lactating women and not a substitute for long-term spacing methods (Kennedy et al., 1991; Labbok, 1991). In addition, in the Indian context LAM can also be seen as a criterion that helps clarify when other spacing methods are needed to protect lactating and/or amenorrhoeic women from unwanted pregnancy.

Doubts have also been raised about the wisdom of promoting lactation in women who are malnourished because of a concern that the energy that is required to adequately meet the nutritional needs of the infant may be directly competing with the nutritional needs of the mother. Research has shown that the best way to counteract such situations is to supplement the caloric intake of the poorly nourished mother and reduce her energy expenditure rather than by early weaning of infants already at risk because of their poor nutritional status (Huffman, 1991; Krasovec, 1991). This not only helps the infant, but ensures the mother is well nourished. 


\section{A. Postpartum Abstinence}

Cultural practices, occupation and urbanization patterns influence the period of postpartum nonsusceptibility to pregnancy. The prevalence of breastfeeding and the duration of postpartum abstinence are usually culturally prescribed. There are large variations in the duration of postpartum abstinence in India (Table 2).

Social norms prescribe a period of sexual abstinence until the woman has completely stopped bleeding, or has completed the ritual period of confinement. The NFHS report for India shows that the duration of postpartum abstinence is longer in south and western India, than elsewhere in the country. The practice of the mother and child visiting her natal family soon after confinement is often the means of insuring postpartum abstinence. In UP, the median duration of postpartum abstinence is 2.9 months, which is shorter than the median for the country, 3.4 months (NFHS, 1995).

\section{B. Frequency of Breastfeeding Episodes}

Research on lactational amenorrhoea has shown that one of the most important factors in the fertility inhibiting effect of breastfeeding is the frequency and duration of feeds. In general, breastfeeds in India are on demand and, since the infant sleeps in the same bed as its mother, feeds in the night are common. The average number of suckling episodes per day for infants aged 0-3 months was estimated to be 8.6 in Maharashtra, 9.5 in West Bengal and 5.4 in Tamil Nadu (Gopujkar et al., 1984). The NFHS report for UP states that 95 percent of children under six months were breastfed six or more times on the day before the interview. Table 3 shows regional variation in breastfeeding patterns. There is no significant difference between urban and rural results on ever breastfed. 
Table 2: Postpartum Nonsusceptibility in Selected States of India

\begin{tabular}{|c|c|c|c|c|c|}
\hline \multirow[t]{2}{*}{ State } & \multirow{2}{*}{$\begin{array}{l}\text { Median } \\
\text { months } \\
\text { amenorr- } \\
\text { hoeic }\end{array}$} & \multicolumn{2}{|c|}{ Percent Amenorrhoeic at: } & \multicolumn{2}{|c|}{ Percent Abstaining at: } \\
\hline & & 6 months & 12 months & 6 months & 12 months \\
\hline All India & 9 & 59 & 30.5 & 24 & 10.9 \\
\hline Punjab & 4.1 & 30.6 & 13.3 & 4.2 & 4.4 \\
\hline Rajasthan & 8 & 57.2 & 25.9 & 11.6 & 8.9 \\
\hline Uttar Pradesh & 8.9 & 57.5 & 22.6 & 28 & 7.7 \\
\hline Bihar & 9.9 & 65.8 & 29.7 & 19.7 & 10.3 \\
\hline Madhya Pradesh & 8.3 & 60.6 & 35.7 & 12.9 & 8.4 \\
\hline Assam & 10.2 & 73.2 & 43.3 & 15 & 7.4 \\
\hline West Bengal & 9.5 & 66.8 & 36.9 & 12.4 & 3.5 \\
\hline Maharashtra & 8.5 & 56.8 & 31.2 & 31.8 & 13 \\
\hline Gujarat & 8.9 & 58.2 & 24.1 & 24.6 & 12 \\
\hline Goa & 4.1 & 36 & 5.1 & 49.4 & 19 \\
\hline Kerala & 5.4 & 40.3 & 12.7 & 32.3 & 9.5 \\
\hline Tamil Nadu & 5.6 & 35.6 & 19.3 & 42.5 & 19.30 \\
\hline
\end{tabular}

Source: NFHS, 1992-93 (1995).

Although the duration of exclusive breastfeeding is close to the duration of full or nearly full breastfeeding considered necessary for practicing LAM, awareness of the fertility reducing effects of early full and frequent breastfeeding is quite low. A study conducted in Gujarat to assess the perception of working mothers towards breastmilk shows that only 14 percent of women in rural areas thought that breastfeeding delays pregnancy. This figure was 41 percent in urban areas (Khan and Basu, 1987). 
Table 3: Breastfeeding Patterns in India

\begin{tabular}{||l|c|c|c||}
\hline State & \% Ever breastfed & $\begin{array}{l}\text { \% Exclusively } \\
\text { breastfed } \\
\text { At 6 months }\end{array}$ & $\begin{array}{l}\text { \% Breastfed + } \\
\text { water only } \\
\text { At 6 months }\end{array}$ \\
\hline All India & 95.4 & 20.2 & 24.6 \\
\hline Punjab & 95.7 & 0 & 17.9 \\
\hline Rajasthan & 95.9 & 31.9 & 24.4 \\
\hline Uttar Pradesh & 95.3 & 28.7 & 16.9 \\
\hline Bihar & 95.1 & 17.7 & 38 \\
\hline Assam & 96.1 & 26.7 & 4.9 \\
\hline Gujarat & 97.0 & 10.3 & 32.8 \\
\hline Goa & 96.7 & 5.5 & 5.5 \\
\hline Kerala & 97.8 & 1.7 & $<0.05$ \\
\hline Tamil Nadu & 94.7 & 3.8 & 12.70 \\
\hline
\end{tabular}

Source: NFHS 1992-1993 (1995).

\section{Reasons for Early Discontinuation of Breastfeeding}

Although the practice of prolonged breastfeeding is common in India, there is a small but significant population that stops breastfeeding early, either due to constraints such as barriers to breastfeeding in the workplace or traditional cultural practices. These groups are significant because they point to changes in breastfeeding patterns and the need for special attention.

\section{Mother's work}

Working mothers may stop breastfeeding because of a lack of child care facilities at their place of work. A large number of women in private industry are unable to continue full breastfeeding beyond their entitled maternity leave, while some women are forced to stop feeding because they are not entitled to any paid leave.

\section{Maternal illness}

Maternal illness, such as fevers and digestive ailments, is also a reason for early cessation. Women fear that the disease will be transferred to the child or that medicines will influence milk composition. Cessation of breastfeeding under such conditions jeopardizes the health of the ailing mother (due to greater likelihood of breast engorgement and infections) as well as the breastmilk-deprived infant. 


\section{Pregnancy}

In India, as in other countries, breastfeeding is stopped if the woman becomes pregnant. This is done because it is thought to deprive the foetus of nutrition, and not be good for the breastfed child. Thus bottle feeding in the early postpartum period poses a triple risk; the young infant is deprived of breast milk, the woman is at risk of all problems related with short interval between pregnancies, such as anaemia; and an early pregnancy may retard foetal growth.

\section{Infant's illness}

Local beliefs about the composition of maternal milk and its association with the health of the infant also influence breastfeeding practices. Studies on infant diarrhoea in India have noted the custom of stopping feeds when a child has diarrhoea. This practice extends to other illnesses as well. This puts the infant at double risk: of being deprived of maternal antibodies and nutrition through breast milk as well as exposing the child to illnesses which may be caused by the unhygienic methods of supplementary feeding.

\section{GUIDELINES FOR OPERATIONAL POLICIES TO INCLUDE LAM IN UP}

In India initiation of breastfeeding is nearly universal; however, the length of exclusive breastfeeding varies considerably. In UP 16 percent of infants receive some food supplement other than water at two months and 27 percent at three months (NFHS, 1995). Under these conditions the assumption that breastfeeding is universal, and therefore no active encouragement for full breastfeeding is required, is clearly not based on empirical data. Full breastfeeding for at least the first four to six months postpartum needs to be actively promoted in Uttar Pradesh. LAM is one method to promote improved breastfeeding practices in the early months postpartum. The ANMs knowledge about LAM needs to be strengthened throughout UP. A thorough review of the counselling process must take place to make sure that ANM's understand when and how lactation can act as an effective contraceptive. Education about complementary feeding should be provided along with information on modern contraceptive methods by four months, even while amenorrhoea and partial breastfeeding continues.

The pregnancy-based approach encourages health care providers to discuss family planning options with pregnant and lactating women while providing maternal and child health services. It is important that they give these women a consistent message which encourages full breastfeeding while explaining the risk of pregnancy and the need to use a spacing method when LAM criteria are no longer met should be part of LAM counselling. Thus it is important that health care providers receive training in LAM and, most importantly, that policy makers and providers clearly understand when other complementary contraceptive methods should be advised to ensure continuity of protection from unplanned pregnancy. The following are commonly raised queries. 
Yes, if breastfeeds precede each feeding of a supplement and breastfeeding frequency remains high. In the child health literature it is clear that the nutritional requirements of infants can be met by full breastfeeding until six months in wellnourished mothers. However, a less well-nourished lactating woman may require additional calories in order to meet both her own energy needs and the needs of the infant. Therefore, the Child Survival and Safe Motherhood (CSSM) program in India encourages initiation of weaning at four months. The two messages should be consistent and, therefore, in the CSSM and Family Welfare programme women understand the need to use a contraceptive method compatible with breastfeeding once substantial calories in the infant's diet are obtained from food supplements and the frequency and intensity of breastfeeds have decreased.

\section{- What are the Mechanisms for Pproviding Information to Women about LAM?}

Presently available mechanisms for dissemination of information and training existing within the Family Welfare Programme should be used. Education on LAM and other contraceptive options appropriate for the postpartum period must be provided by ANMs and doctors to pregnant mothers, spouses, and other family members. Hospitals must be made 'baby and mother friendly' and sensitised concerning the role of LAM. Traditional birth attendants must be trained about LAM; Anganwadi workers can arrange mothers' group meetings to educate them about LAM, and ANMs should mention it while providing antenatal and child care. Physicians should receive training on when LAM is appropriate and when another method needs to be advised.

\section{- What are some Common Provider Misconceptions about when Contraception should be Encouraged among Breastfeeding Women?}

Provider misconceptions about the need for contraception during lactation are often based on a lack of knowledge of the exact physiological mechanisms of LAM and the influence of contraceptives on lactation. Family planning updates must address these misconceptions in a scientific way. It is clear that breastfeeding is very important for an infant's health and survival, and therefore any contraceptive measure that decreases breast milk output, or decreases the duration of breastfeeding, must be avoided. At the same time, the fertility-inhibiting effect of breastfeeding is reliable only during the first six months of full or nearly full breastfeeding among women who have lactational amenorrhoea, even if a woman continues to breastfeed her infant beyond one year. ANMs must clearly understand that their counselling message should be to begin supplementing the infant's diet and start using another method of contraception such as condoms or an IUD whenever any one of the three LAM criteria is no longer met.

\section{Can Postpartum Amenorrhoea before Six Months be Considered Sufficient Indication of Anovulation for IUD Insertion or Tubectomy?}

Amenorrhoea in the postpartum period is physiologically linked with lactation and many women and lay practitioners consider it a sign that ovulation has not yet resumed. Amenorrhoea alone, however, does not constitute complete proof of anovulation. 
Studies have found that ovulation occurred before mensuration in 45 percent of women who breastfed their infants (Howie et al., 1982 cited in Winikoff and Mensch, 1991). Such data have led many to believe that lactational amenorrhoea is an unreliable indicator of anovulation. However, the Lactational Amenorrhea Method advocates the use of three criteria and not just lactational amenorrhoea to assess pregnancy risk. A fourth parameter also applies - the woman understands that even if one of the three criteria are not met she is at risk of pregnancy and should discuss birth spacing with her spouse and start using a family planning method that is complementary to breastfeeding.

ANMs and physicians are often hesitant to provide amenorrhoeic women a choice of methods, particularly, IUDs and Tubal ligation. A beneficial side-effect of LAM is increased breastfeeding and confidence that an amenorrhoeic woman is not pregnant. This decreases the need for pregnancy tests prior to insertion of an IUD or sterilization in an amenorrhoeic, fully breastfeeding woman at, or before, six months postpartum.

\section{OPERATIONAL ISSUES FOR SERVICE DELIVERY}

The following are ways in which the two main issues surrounding LAM information, education and communication can be addressed, and LAM can be included in the Family Welfare Programme in UP.

\section{- Postpartum Women in Uttar Pradesh are not Aware of LAM}

Women in UP currently do not know under what conditions breastfeeding provides protection against pregnancy. Additionally, they need information about when to start using a spacing method for greater protection, even when they are still amenorrhoeic.

\section{Action}

Increase awareness among women, their spouses and the community that LAM is 98 percent or more effective for up to six months postpartum.

- Women should be encouraged to continue full breastfeeding during the day and night because LAM's effectiveness is directly related to the duration and frequency of breastfeeding episodes. When food supplements need to be added to the infant's diet, they should be given after breastfeeds.

- Women working outside the home need special attention as they are at greater risk of pregnancy because of early weaning.

- IEC efforts should inform women about their increased risk of pregnancy if LAM conditions are not met, and the contraceptive options for birth spacing.

- Inform men about the importance of breastfeeding and birth spacing for their family's health and welfare. 


\section{- Providers do not yet Include LAM as a Postpartum Contraceptive Option}

Situation analysis in UP showed that different types of providers were more likely to recommend one family planning method over another. None cited LAM as a method.

\section{Action}

LAM and fertility awareness updates should reach all levels of service providers to strengthen family planning counselling and facilitate the adoption of spacing methods.

- Provide education on LAM at every CSSM/MCH and reproductive health training course for Health Workers (ANMs, LHVs and male workers) and Medical Officers.

- Include LAM in all traditional birth attendant and child development worker training programmes.

- Inform health care providers about the physiological basis of LAM so that they understand and counsel effectively on the importance of full or nearly full breastfeeding.

- Train District Hospital and Postpartum Centre staff in LAM counselling. Add LAM to the health education messages given to women who have institutional deliveries.

\section{CONCLUSION}

LAM is a well researched and effective method of postpartum contraception. Since it benefits the mother and the child, it is an ideal means to introducing spacing methods to couples in the peak fertility age group. Because practices related to breastfeeding benefit child health as well as maternal health, it is important that all steps taken to introduce postpartum contraception carefully include messages that promote breastfeeding and the use of LAM, besides other postpartum contraceptive options. Also methods complementary to breastfeeding should be available once LAM criteria are no longer fulfilled.

\section{ACKNOWLEDGMENTS}

The authors would like to acknowledge valuable comments from Miriam Labbok, Karen Stein, Wilda Campbell, Saroj Pachauri, M.E. Khan, J ayanti Tuladhar, Saumya RamaRao, R.B. Gupta, Bella C. Patel and formating assistance from Sanjeev Kumar and V.L. Thomas. 


\section{REFERENCES}

Bellagio Consensus Statement (1995). Lactational Amenorrhea Method for Family Planning.

Bellagio, Italy 11-14 Dec.1995, WHO, FHI \& IRH.

Bellagio Consensus Statement (1988). Breastfeeding as a family planning method. The Lancet, 19 Nov. 1988.

Bhatia, Shushum, and Y. Kim (1984). Oral contraception in Bangladesh. Studies in Family Planning $15,5: 233-241$.

Blumenthal, Paul D. and N. McIntosh (1995). Pocket Guide for Family Planning Service Providers: JHPIEGO Corporation. Baltimore.

Bracher, M. (1992). Breastfeeding, lactational infecundity, contraception and the spacing births: Implications of the Bellagio consensus statement. Health Transition Review, 2, 1: 19-47.

Bruce, J. (1989). Fundamental elements of the quality of care: A simple framework. Programs Division. Working Paper No.1: The Population Council. New York.

BSUP (1995). District level survey of family planning program in Uttar Pradesh. SIFPSA, Lucknow, The Population Council, India.

CSD and PC. (1995). Situation Analysis of Family Welfare Program in Uttar Pradesh: Agra, and Sitar District. Final Report, Council for Social Development, New Delhi and The Population Council ANE OR/TA. New Delhi. December 1995.

Gopujkar, P.V., S.N. Chaudhuri, M.A. Ramaswami et al. (1984). Infant feeding Practices with Spedal reference to the Use of Commercial Infant Foods. Scientific Report, Nutrition Foundation of India.

Hatcher, R.A., J. Trussell, F. Stewart et al. (1994). Contraceptive Technology 16th Revised Ediion. New York: Irvington Publishers Inc.

Howie, P.W., A.S. McNeilly, M.J. Houston et al. (1982). Fertility after childbearing: Postpartum ovulation and menstruation in bottle and breastfeeding mothers. Clinical Endocrinology 17:323-332 cited in Winikoff, B and B. Mensch (1991). Rethinking Postpartum Family Planning. Studies in Family Planning 22,5: 294-307.

Huffman, S.L. (1991). Maternal malnutrition and Breastfeeding: Is there really a choice for policy makes Journal of Tropical Paediatrics. Vol 37, Supp Oct 1991, pp 19-22.

Hull, V.J. (1981). The effects of hormonal contraceptives on lactation: Current findings, methodological considerations, and future priorities. Studies in Family Planning 12,4: 135-155.

Karra, Mihira and J. Spieler (1992). Breastfeeding as part of the UP Project. Information Memorandum, USAID.

Kennedy, K.I., R. Rivera and A.S. McNeilly (1989). Consensus statement on the use of breastfeeding as a family planning method. Contraception 39(5):477-496.

Kennedy, K.I, R. Rivera, and S. McNeilly (1991). Rejoinder to Trussell and Santow, Health Transition Review, 1: Pg.107-110.

Khan, M.E. (1990). Breastfeeding and weaning practices in India. Asia-Pacific Population Journal 5,1:7188.

Khan, M.E. and J.K. Basu (1987). Breastfeeding Among Working Women in Organized and Unorganized Sector. Report submitted to ICMR, New Delhi, Operations Research Group, Baroda.

Krasovec K. (1991). The implications of poor maternal nutritional status during pregnancy for future lactational performance Journal of Tropical Paediatrics, Vol.37, Supp. Oct. 1991, pp. 3-10.

Labbok M.H. (1991). Breastfeeding and borderline malnutrition in women. Journal of Tropical

Paediatrics Vol. 37, Supp. Oct. 1991, pp. 23-24.

Labbok, Miriam (1991). Rejoinder to Trussell and Santow. Health Transition Review Vol.1 No.1, Pg111114.

Labbok, Miriam H. (1993). The lactational amenorrhoea method (LAM): a new hormonal family planning method. In Senanayake and R.L. Klienman (eds.), Family Planning, Meeting Challenges: Promoting Choices, The Proceedings of the IPPF Family Planning Congress. New Delhi, October 1992.Parthenon Publishing Group: Carnforth,U.K.

Labbok, M.H, K. Cooney and S. Coly (1994). Guidelines: Breastfeeding, Family Planning and Lactational Amenorrhoea Method (LAM). IRH, Washington, pp. 5.

Merrick, Thomas W. (1993). Breast feeding in family planning: why? In Senanayake and R.L. Klienman (eds.) Family Planning, Meeting Challenges: Promoting Choices, The 
Proceedings of the IPPF Family Planning Congress New Delhi, October 1992. Parthenon Publishing Group: Carnforth, U.K.

Ministry of Health and Family Welfare (1992). National Child Survival and Safe Motherhood

Programme: Module for Health Workers MCH Division, Ministry of Health and Health and Family Welfare, New Delhi: New Delhi.

National Family Health Survey 1992-93 (1995). Uttar Pradesh National Family Health Survey.

Population Research Centre, Lucknow University, Lucknow and International Institute for

Population Sciences.

RamaRao, Saumya (1992). Evidence from Peninsular Malaysia of Breastfeeding as a Contraceptive Method. Studies in Family Planning 23, 6:376-385.

Ross, John A. and Elizabeth Frankenberg (1993). Findings from Two Decades of Family Planning Research. New York: The Population Council.

Thapa, Shyam., Roger V. Short and Malcolm Potts (1988). Breastfeeding, Birth Spacing and Their Effects on Child Survival. Nature 1962, p. 679.

Toddywalla, V.S., S. Mehta, K.D. Virkar and B.N. Saxena (1980). Release of 19-nor-testosterone type of contraceptive steroids through different drug delivery systems into the serum and breast milk of lactating women. Contraception 21, 3: 217-223.

Trussell, James and Gigi Santow (1991). Is the Bellagio consensus statement on the use of contraception sound public-health policy. Health Transition Review 1,1: pg. 105-107.

WHO (1994). Safe Motherhood Mother Baby Package: Implementing Safe Motherhood in Developing Countries. Maternal Health and Safe Motherhood Programme. Division of Family Health.

WHO (1990). Task Force on Oral Contraceptives, Special Programme of Research, Development, and Research Training in Human Reproduction. Studies in Family Planning 19, 6: pg 361369

Winikoff, Beverly, P. Semeraro, and M. Zimmerman (1988). Contraception During Breastfeeding: $A$ Clinician's Source Book. New York: The Population Council.

Winikoff, B and B. Mensch (1991). Rethinking postpartum family planning. Studies in Family Planning 22,5: 294-307. 